\title{
Toward a Unified Grammar of Reference*
}

\author{
GIUSEPPE LONGOBARDI
}

\section{Abstract}

The unification of traditionally distinct and apparently unrelated objects of inquiry under common more abstract principles is one of the most welcome results of empirical science. This article proposes to draw together some insights of Longobardi (1994, 1996, 2001) into a unified theory of objectand kind-reference viewed as a single grammatical phenomenon, though crosslinguistically parametrized. The present account aims to improve both in accuracy and explanatory force over those outlined in the articles just cited. ${ }^{1}$ To do so, the combined leading intuitions of such works are first spelt out, in section 6, into a deeper generalization about the form/meaning relation in nominals and later deduced from a more principled mapping theory, proposing that a syntactically specified position, traditionally labeled $D$, is responsible in many languages for one of human fundamental linguistic abilities, reference to individuals (Topological Mapping Theory). After the unification of the syntactic mechanisms available for reference to individuals, virtually all other distinctions simply follow precisely from that between the two varieties of such entities (kinds and objects) previewed in Carlson's (1977a) ontology, indirectly confirming its continuing heuristic power, and from widely accepted economy conditions of recent syntactic theory.

* Some of these ideas have appeared in a volume edited by Elisabetta Fava (Fava 2001), to whom I am grateful for allowing and encouraging me to work out this more elaborate version. I am also indebted to Denis Delfitto and Susan Rothstein, for useful comments on a presentation of such matters at the OTS (Utrecht University), and to the UCLA Linguistics Department, for hosting me once again during the completion of this article. I wish to dedicate this modest contribution to Noam Chomsky on the occasion of his $75^{\text {th }}$ birthday.

1. The increased empirical accuracy in the theory of bare nouns has greatly benefited from insights of Dobrovie-Sorin \& Laca (1996), Chierchia (1998), Delfitto (2002). 


\section{Bare Nouns and Proper Names}

In many languages, nouns may normally occur under a singular or plural form and, when morphologically singular, are subject to either a mass or a count interpretation. In most modern Romance varieties, exemplified by Italian throughout this paper, all three such instances of head nouns may occur superficially determinerless (not overtly introduced by any member of a class of mutually exclusive items called determiners: most usually a definite or indefinite article, a quantifier or a demonstrative) $)^{2}$ in argument function, but their semantic behavior seems to characterize two pretheoretically well distinguishable classes of arguments (in principle whole phrases, not necessarily consisting of just a lexical head):

1. Determinerless arguments characterized by singular non-mass interpreted head nouns appear to denote a definite (roughly, unique in the domain of discourse), specific entity (i.e., a particular object of experience), tend to be rigid designators in Kripke's (1980) sense (they denote the same entity in all conceivable worlds), and are always maximally scope-external (no logical operator or intensional context may take them within its scope) ${ }^{3}$ : henceforth such phrases will be referred to as PNs (suggesting 'proper names').

2. Determinerless arguments characterized by mass or plural head nouns never denote a definite specific entity and in certain instances cannot assume scope over any logical operator (a scopal property not to be confused with the previous one); henceforth such phrases will be termed BNs (bare nouns).

(1) and (2) exemplify the two classes, respectively:

(1) Ho incontrato Maria/te. 'I met Maria/you.'
a. Bevo sempre vino.
'I always drink wine.'
b. Ho mangiato patate.
'I ate potatoes.'

2. For the present purposes we will class among determiners also cardinals and certain quantity expressions, such as molto 'much', poco 'little', or abbastanza 'enough'. For subtler distributional distinctions among determinerlike expressions cf. Crisma (1991), Szabolcsi (1994), Longobardi (2000a) among others.

3. If the argument phrases are not technically headed by the noun (Abney 1987), 'characterizing' must be equivalent to 'being the highest head noun in a transitive complementof relation to the actual head of the argument'. 
The former category of nominal heads is severely lexically defined (though in a definitely non-trivial way, cf. section 4 below), the majority of nouns appearing in the latter category, with some qualifications and apparent overlappings to be discussed later.

In all the Romance languages the surface syntax of the two types of phrases also differs: the first type occurs with a virtually unrestricted distribution, while the second type is confined to so-called lexically governed environments (essentially the same ones where traces may occur). Furthermore, there is at least one Romance variety, modern French, where class 2 . is straightforwardly impossible. ${ }^{4}$

Hence, as a first approximation, the full clusters of properties identifying the two classes of determinerless nominals in argument function are the following: 5
a. singular count reading
b. definite specific interpretation
c. free distribution
d. widest possible scope (de re in all intensional contexts)
e. rigid designation
f. lexically restricted access to the determinerless construction
a. plural or mass reading
b. indefinite interpretation (existential or generic) ${ }^{6}$
c. distribution constrained by lexical-government
d. narrowest possible scope
e. non-rigid designation
f. lexically general access to the determinerless construction

We will start by focusing on the syntax and semantics of PNs. A sentence like (5) happens to instantiate directly all the properties listed in (3):
Non credo che Maria verrà.
'I don't believe that Maria will come.'

\section{N-raising to $D$}

Provided that most nominal arguments in a language like Italian superficially occur in the form $\mathrm{D}$ (eterminer)- $\mathrm{N}$ (oun), a first natural question

\footnotetext{
4. Cf. Delfitto \& Schroten (1991), but also Roodenburg (2003).

5. In at least one Romance language, Brazilian Portuguese, the properties of class 2 . seem to be much less constrained than stated in (4). For some important insights cf. Munn \& Schmitt (1999a, 1999b). For European Portuguese now also cf. Müller \& Oliveira (2004).

6. Cf. Longobardi (2000b, 2001), refining previous insights by Diesing (1992), Longobardi (1994), and Chierchia (1998).
} 
is whether determinerless arguments occur in a structure D-N as well and, if so, whether the noun surfaces under $\mathrm{N}$ or under $\mathrm{D}$.

To examine the point empirically, recall that several Romance varieties display near-free (actually stylistically, if not grammatically or dialectally conditioned) alternations between the presence and the absence of the article with proper (first or last) names of human beings, especially those of famous cultural and historical characters in standard Italian:
a. Petrarca è uno dei miei poeti preferiti.
'Petrarch is one of my favorite poets.'
b. Il Petrarca è uno dei miei poeti preferiti. 'The Petrarch is one of my favorite poets.'

(6a) is the typical sentence exemplifying the properties (3).

The question which arises here, apparently never raised until Longobardi (1991, 1994), is whether Petrarca of (6a) occupies the same surface position as Petrarca of (6b) or rather as il of (6b). To determine the exact location of a lexical item, choosing between two possible structural positions in the tree, it is often useful to insert some overt material between them in order to visualize the abstract linear order; for example, Emonds (1978) and Pollock (1989) relied on interpolation of adverbs and negation to establish that a synthetic (tensed) lexical verb in French occupies the same position as the inflected auxiliary and not as the past participle of the corresponding analytic construction. An argument in the same vein was reproduced in Longobardi (1994) for the positions $\mathrm{N}$ and D. Notice, first, that Italian adjectives, both possessive and nonpossessive ones, may occur in prenominal position between $\mathrm{D}$ and $\mathrm{N}$, or in postnominal position, but never before $\mathrm{D}$ with either common or proper nouns: ${ }^{7}$
a. *mio il Gianni
'my the Gianni'
b. *vecchio il tavolo
'old the table'
Now, consider the following paradigm:
a. Il mio Gianni ha finalmente telefonato.
'The my Gianni finally called up.'
b. *Mio Gianni ha finalmente telefonato. 'My Gianni finally called up.'

7. In Italian, the distributional properties of possessives are roughly similar to those of prenominal attributive adjectives. For a discussion cf. Crisma (1991) and Giorgi \& Longobardi (1991: ch. 3). 

c. Gianni mio ha finalmente telefonato.
'Gianni my finally called up.'
d. Il Gianni MIO ha finalmente telefonato.
'The Gianni my finally called up.'

The double possibility of surface ordering (AN or NA) is preserved when the noun, here in a typical argument position, is introduced by the determiner, but an unexpected gap in the paradigm appears with articleless names: in fact, while many speakers, especially but not exclusively in the Center and the South of Italy, perfectly accept (8c), none accepts (8b). The generalization appears to be that the lack of the article forces an Ninitial order. This otherwise surprising idiosyncrasy becomes immediately understandable assuming that the proper name needs to move from $\mathrm{N}$ in order to fill in the empty $\mathrm{D}$ position, thus crossing over adjective presumably lying in intermediate Spec positions. ${ }^{8}$ There is also semantic evidence that the possessive AP of (8c) does not follow the normal position of determined nouns and has become superficially postnominal only as the result of an N-preposing process: normal postnominal possessives tend to be strongly contrastive in Italian, as is the case e.g., for mio (notated in capital letters) in (8d), which can only be interpreted with contrastive reference to the existence of another salient Gianni in the domain of discourse who is not 'mine', i. e., is related to someone else. This interpretation is not required, instead, by prenominal possessives, like the one in (8a), which can be perfectly understood as an affective expression in an environment where no other Gianni's existence is presupposed. Now, the interpretation of mio in $(8 \mathrm{c})$ does not need to be contrastive, exactly like that in (8a) and contrary to that in (8d). This may be explained on the grounds of the general fact that contrastiveness is uniformly required in Italian of possessives occurring after $\mathrm{D}+\mathrm{N}$ but not of those occurring between $\mathrm{D}$ and $\mathrm{N}$, along with the crucial hypothesis that it is Gianni that moved up to D in (8c), crossing over mio.

The paradigm above can be exactly reproduced with certain non-possessive adjectives too; ${ }^{9}$ here are examples with a city name as the raising head:

a. L'antica Roma fu la città più importante del Mediterraneo. 'The ancient Rome was the most important city of the Mediterranean.'

8. A basically prenominal position for adjectives in Romance was proposed by Crisma (1991, 1996), Valois (1991), Bernstein (1992, 1993).

9. Even in the more 'liberal' varieties of Central and Southern Italy not all adjectives allow the raising of the head noun: indeed, modification by many types of adjectives blocks the movement and imposes the use of the article also with proper names. Actually, it seems that the only adjectives which tolerate determinerless proper names are those which receive a restrictive interpretation: therefore, the significant tests in favor of $\mathrm{N}$ - 
b. *Antica Roma fu la città più importante del Mediterraneo. 'Ancient Rome was the most important city of the Mediterranean.'

c. Roma antica fu la città più importante del Mediterraneo. 'Rome ancient was the most important city of the Mediterranean.'

d. La Roma ANTICA fu la città più importante del Mediterraneo.

'The Rome ancient was the most important city of the Mediterranean.'

Also names of months and days reproduce an analogous pattern of behavior across virtually all the principal Romance languages and dialects, whose properties will be discussed in section 4 below.

The best evidence for $\mathrm{N}$-raising should in principle be provided by adjectives normally only occurring prenominally whenever a determiner is present, but postnominally when modifying a determinerless PN. The adjective solo (masc. sing., but regularly inflected for gender and

to-D must and can be performed with the few ones which may normally achieve a restrictive reading even in prenominal position after a determiner (a possibility often barred for the majority of Italian adjectives): namely possessives, adjectives like vecchio 'old', giovane 'young', antico 'ancient', solo 'only' and numeral ordinal adjectives. As for the latter, it is plausible that an idiomatized version of N-raising lies behind the usage of names of monarchs and popes followed by an ordinal adjective: for ordinal adjectives obligatorily occur in prenominal position except with such nouns when articleless. Cf. for example the alternation in the following pair:

(i) a. Napoleone terzo / *Terzo Napoleone fu l'ultimo Imperatore dei Francesi.

'Napoleon third / Third Napoleon was the last Emperor of the French people.'

b. Il terzo Napoleone / *Il Napoleone terzo computato nella dinastia si chiamava in realtà Luigi Bonaparte.

'The third Napoleon / The Napoleon third numbered in the dynasty was actually named Luigi Bonaparte.'

A few other near-lexicalized cases of N-to-D could involve crossing of the noun over another noun, functioning as a formulaic epithet, and be instantiated by the following alternations:

(ii) a. Il bambino Gesù / Gesù bambino / *Bambino Gesù nacque a Betlemme.

'The baby Jesus / Jesus baby / Baby Jesus was born in Bethlehem.'

b. La Vergine Maria / Maria vergine / *Vergine Maria partorì a Betlemme.

'The Virgin Mary / Mary Virgin / Virgin Mary gave birth in Bethlehem.'

More generally, with all other adjectives determinerless proper names are totally incompatible with any appositive reading and can only be tolerated with the restrictive and sharply contrastive interpretation that such adjectives normally acquire just in postnominal position (e.g., Gianni simpatico 'Gianni nice' can be accepted only if the speaker and hearer agreed in advance to define the individual referred to that way in contrast to another, less nice, Gianni). Therefore such constructions prove nothing about N-to-D. 
number: sola, $-i,-e$, and not to be confused with the homophonous but obviously uninflected adverb meaning 'only, just'), in one of its meanings (i. e., when equivalent to 'only, unique'; in the other acception it means 'alone'), provides a further strong argument for N-raising. In fact, when used with a noun introduced by an article, an inflected (thus unambiguously adjectival) form of solo can only occur prenominally, at least in the intended meaning: ${ }^{10}$

a. La sola assistente / *L'assistente sola gli crede.

'The only (fem. sg.) assistant / The assistant only (fem. sg.) believes him.' ('Only the assistant believes him.')

b. La sola Maria / *La Maria sola gli crede.

'The only (fem. sg.) Maria / The Maria (fem. sg.) only believes him.' ('Only Maria believes him.')

But if the article is dropped, a viable alternative with the proper name, the usual sharp contrast reappears:
a. Maria sola gli crede.
'Maria only believes him.'
b. *Sola Maria gli crede.
'Only Maria believes him.'

These data have seemed to be sufficient, since Longobardi (1991, 1994), to conclude that, for Romance PNs, raising to D is necessary, whenever the latter is lexically empty. The following facts show that $\mathrm{N}$ raising to $\mathrm{D}$ is not necessary instead for BNs:
a. Ho trovato antiche statue dappertutto.
'I found ancient statues everywhere.'
b. Ho trovato bel tempo dappertutto.
'I found good weather everywhere.'

The following paradigms, involving normally steadily prenominal attributes like ordinal adjectives, suggest that $\mathrm{N}$-to-D is not even possible for BNs:
a. Ho incontrato i terzi figli di Gianni e di Paolo.
'I met the third children of Gianni and of Paolo.'

10. The adjective solo can also mean 'alone' and in this case it normally occurs postnominally. 
b. *Ho incontrato i figli terzi di Gianni e di Paolo. 'I met the children third of Gianni and of Paolo.'

a. Ho incontrato terzi figli dappertutto.

'I met third children (i.e., people with exactly two elder siblings) everywhere.'

b. *Ho incontrato figli terzi dappertutto. 'I met children third everywhere.' 11

Hence, N-to-D is obligatory for PNs, impossible for BNs. This crucial distinction must then be added as a further property to the clusters in (3) and (4) respectively.

\section{Reference and proper names}

The discussion above points out that at least in argument function $\mathrm{N}$ to-D raising correlates with a singular-definite specific-transparent-rigid reading of the nominal, i. e., it actually implies most of the properties that the philosophical tradition from the Frege through Kripke (1980) has attributed to classical determinerless proper names.

Instead, the lack of N-to-D raising correlates with the plural/massindefinite-opaque-nonrigid reading which was shown to hold of Romance BNs in Longobardi (2001) among and after many others.

Let me now formally introduce two distinctions on which we will rely throughout in what follows: that between kinds and objects and that between referential (constant) and quantificational (variable) interpretation of arguments.

Carlson (1977a) proposed a distinction between two types of individual entities presupposed by the semantics of natural languages: primitive particular individuals called objects, and a less obvious class of individuals called kinds, which can be tentatively understood as 'maximal sets of entities sharing some properties across all possible worlds'.

Let us suppose further that, semantically, argument phrases are associated to individuals in such a (mental) ontology and call this association denotation or designation. Denotation will come in either of two forms: arguments may be assigned by a function to an entity (kind or object),

11. The few lexical exceptions where an ordinal adjective occurs postnominally with an article confirm the general rule:

(i) a. Ho trovato un'opera prima di un giovane autore sconosciuto.

'I found a work first of a young unknown author.'

b. Ho trovato opere prime dappertutto.

'I found works first everywhere.' 
or to an intensionally definable set of such entities; in the former case their meaning is a constant, in the latter a variable ranging over the members of the set (again kinds or objects, with cardinality ranging from zero to infinite). Let us call denotation as a constant reference, denotation as a variable quantification. ${ }^{12}$

The semantic properties of PNs included in (3) above can naturally be traced back to the fact that they function as constants referring to particular individuals, i. e., objects. Hence, the phrase object-reference will be taken as a short form for the cluster formed by such properties.

Then, at least as far as determinerless arguments are concerned, the following biconditional implication seems to hold:

a. Object reference if N-to-D

b. N-to-D if object reference

(15) is the first main generalization discovered in Longobardi (1991, 1994) about Romance nouns. From a functional perspective, and informally speaking, this suggests that $\mathrm{N}$ raises to $\mathrm{D}$ to perform an objectreferential function in constructions where phrases with non-raised determinerless nouns obligatorily receive a quantificational (indefinite) interpretation (roughly in argument environments; cf. section 5 below). ${ }^{13}$

Conceptually, the validity of (15) is also important because it shows that, at least in this type of languages, proper names' traditional distinctive property of 'dropping the article' is not only the result of their intrinsic semantics but also of their purely syntactic, derivational property of going to occupy the position of the article itself. Also, this casts doubts on the validity in Romance of Burge's (1973) proposal that the semantic properties of proper names (essentially, those summarized by our term 'object reference') are the consequence of some special invisible determiner.

\section{Common nouns and proper names: access to the raising strategy}

As a consequence of (15), functioning object-referentially, i. e., as a PN, is a derivational property of arguments and also a bipolar one. It is

12. Notice that, following Napoli (undated), I will not make any (misleading) terminological distinction between reference and direct reference: reference will be taken as the property of certain expressions of necessarily designating one and only one fixed individual entity (whether kind or object), a property not shared by any description, even singular definite, since the latter do not display the relevant properties of (3), seemingly implying the intervention of a variable in the interpretation (cf. Neale 1990)

13. Technically speaking, it is immaterial at least to the present argument if $\mathrm{N}$ moves to $\mathrm{D}$ as a real $\mathrm{X}^{\circ}$ or as an $\mathrm{X}^{\mathrm{max}}$, since the latter hardly contains any other material than the head in all relevant cases. 
derivational, not simply lexical, in the sense that its occurrence cannot always be predicted just from the lexical features of the head noun. It must be achieved through a precise syntactic strategy, N-to-D, which applies under certain environmental conditions but not others. Also, it is bipolar because using such a strategy or not is clearly a discrete binary alternative: hence in each single derivation a noun will either be used to refer to an object or not.

What remains a lexical property, indeed a restricted one, as noted above, is the possibility of accessing such a strategy. On these grounds it should be possible, in principle, to partition head nouns into proper names and common nouns. However, a closer look seems to show that this type of test, by itself, does not provide just a bipolar contrast but rather a scalar hierarchy from prototypical proper-like to prototypical common-like items.

First of all, notice that the diagnostic paradigm of N-to-D within phrases in argument function, used as a heuristics, immediately identifies three types of items:

a. La sola Padova è stata prescelta tra le città italiane.

'The only (fem.sg.) Padua was selected among Italian cities.'

b. Padova sola è stata prescelta tra le città italiane.

'Padua only (fem.sg.) was selected among Italian cities.'

c. * Sola Padova è stata prescelta tra le città italiane.

'Only (fem.sg.) Padua was selected among Italian cities.'

(17) a. *La sola tu sei stata prescelta tra le concorrenti italiane.

'The only (fem.sg.) you were selected among Italian applicants.'

b. Tu sola sei stata prescelta tra le concorrenti italiane. 'You only (fem.sg.) were selected among Italian applicants.'

c. * Sola tu sei stata prescelta tra le concorrenti italiane.

'Only (fem.sg.) you were selected among Italian applicants.'

(18) a. La sola cucina è stata rifatta di recente (non la camera da letto).

'The only (fem.sg.) kitchen was rebuilt recently (not the bedroom).'

b. *Cucina sola è stata rifatta di recente (non la camera da letto).

'Kitchen only (fem.sg.) was rebuilt recently (not the bedroom).' 
c. *Sola cucina è stata rifatta di recente (non la camera da letto).

'Only (fem.sg.) kitchen was rebuilt recently (not the bedroom).'

The distribution of the asterisks in the examples above should make the generalizations easily detectable even visually.

As a first approximation to be refined below, we may call the heads with the pattern (16) proper names (not to be confused with $P N s$, a term we have reserved for all object-referential argument phrases), those with the pattern (17) pronouns, those with the pattern (18) common nouns.

Thus, a very sharp divide separates pronouns from all the other items, since the latter, given appropriate conditions, may all display the behavior typical of common nouns: even classical proper names may occur with all sorts of overt determiners and may be used as bare plurals with all the properties of (4), including the lack of N-to-D, while pronouns never tolerate an overt determiner and always retain the properties (3). In a typical environment in which proper names must be treated exactly as common nouns, i.e., under restrictive relative modification, normal pronouns are just ungrammatical:
a. Il (simpatico) Gianni che conoscevo non esiste più.
'The (nice) Gianni that I used to know no longer exists.'
b. *Gianni (simpatico) che conoscevo non esiste più.
'Gianni (nice) that I used to know no longer exists.'
c. *Il (simpatico) lui che conoscevo non esiste più.
'The (nice) he that I used to know no longer exists.'
d. *Lui (simpatico) che conoscevo non esiste più.
'He (nice) that I used to know no longer exists.'

An analogously sharp, but opposite, divide separates normal common nouns from the other items, since they never raise to D. A distinction between common and proper appears possible, then, on such grounds, although the system is at least tripartite.

The hierarchy of prototypicality is far more structured, though. As noticed in Longobardi (1994), the names of certain temporal units, e. g., of weekdays, holidays, months, are raising nouns. On the surface they exactly reproduce the paradigm of person and place names as instantiated in (16):

(20) a. Il prossimo lunedì sarà il giorno più impegnativo della settimana.

'The next Monday will be the busiest day of the week.' 
b. Lunedì prossimo sarà il giorno più impegnativo della settimana.

'Monday next will be the busiest day of the week.'

c. *Prossimo lunedì sarà il giorno più impegnativo della settimana.

'Next Monday will be the busiest day of the week.'

However, even when the (deictic) adjective is dispensed with, the determinerless (presumably raised) occurrence of lunedi is necessarily understood as deictic, i. e., as referring to the last or immediately next Monday, unless the date is fully specified, as in (21b); a looser specification as in (21c) tends to make N-to-D degrade in grammaticalness; the version of the sentence with the article (hence, certainly, a non raised lunedi) can, instead, predicate a property of a specific Monday far away in time:
a. Lunedì sarà / è stato il giorno più duro.
'Monday will be / was the hardest day.'
b. Lunedì 6 maggio è stato il giorno più duro.
'Monday May 6th was the hardest day.'
c. ??Lunedì della prima settimana dello scorso anno è stato il giorno più duro.
'Monday of the first week of last year was the hardest day.'
d. Il lunedì sarà / è stato il giorno più duro (di quella setti- mana).
'The Monday will be / was the hardest day (of that week).'

The full range of possibilities is probably even more complex and the judgments variable, but this should be enough to show that with certain head nouns the lexical matrix by itself does not suffice to ensure the occurrence of the properties necessary to achieve object reference (hence to undergo N-to-D), first of all the presumption of uniqueness in the domain of discourse. Such head nouns become object-naming under certain environmental conditions: they are in some sense intermediate between classical proper names and common ones.

The most revealing and structured case of such nouns has been studied in Longobardi (1996). In several varieties of Italian the names for 'home', casa, and for close kinship relations, e.g., mamma and papà, give rise to the diagnostic pattern of $\mathrm{N}$-to-D: ${ }^{14}$

14. Cf. Longobardi (1996) for the analysis of a larger class of Italian kinship expressions, such as mia sorella 'my sister', also likely to involve N-raising along with further syntactic manipulation. 

a. La mia casa è qui vicino.
'The my home is nearby.'
b. Casa (mia) è qui vicino. 'Home (my) is nearby.'
c. *Mia casa è qui vicino.
'My home is nearby.'

However, in their raised occurrences, these common nouns display the peculiarity that they must always be interpreted as discharging a possessor semantic role on an overt or understood genitive modifier (an overt possessive adjective, a ' $d i+$ DP' phrase, or, presumably, some pronominal empty category subject to arbitrary, pragmatic, or control reading: the five cases are exemplified below in the same order):
a. Casa mia è bellissima.
'Home my is wonderful.'
b. Casa di Gianni è bellissima.
'Home of Gianni is wonderful.'
c. Casa è sempre il posto migliore per rilassarsi.
'Home is always the best place to relax (= one's home).'
d. Casa era ormai vicina.
'Home was eventually nearby (= my/your/his/her home, according to pragmatic saliency).'
e. Maria pensa che la madre di Gianni abbia ripulito casa. 'Maria thinks that Gianni's mother has cleaned up home (= Gianni's mother's home, unless Maria or Gianni are pragmatically salient).'

Thus, such nouns may access the syntactic strategy of N-to-D, entitling them to object reference, but only if their referential domain (the domain over which they must refer uniquely) is independently restricted by a syntactically (though not necessarily phonologically) active genitive modifier. It is remarkable, albeit predictable, that the properties of object reference are observed with these nouns as well, when (and only when) they undergo N-to-D, including e. g., the strong tendency toward a wide scope (de re or non-opaque) reading in intensional contexts displayed in (24a) as opposed to (24b):

(24) a. Gianni vorrebbe poter finalmente entrare in casa nuova. 'Gianni would like to be finally able to get into home new.'

b. Gianni vorrebbe poter finalmente entrare nella nuova casa. 'Gianni would like to be finally able to get into the new home.' 
This reinforces once more the fundamental correlation established in (15).

The rough and incomplete observations above should suffice to prove that we have to do with a scalar, not a bipolar, property, essentially in the sense of Timberlake (1977); nominal expressions are lexically ranked along a potentially universal scale departing from a prototype and perhaps having to do with relative richness in descriptive content. On the grounds of such limited observations about N-to-D in Italian it is already possible to sketch some tentative steps of the relevant hierarchy, from the most prototypically 'proper-like' items down: ${ }^{15}$
a. Pronouns: are in D in all argument environments.
b. Names of persons, geographical units and many others: raise to $\mathrm{D}$ if and only if the latter does not contain a lexical deter- miner.
c. Names of days: raise to D only under particular semantic conditions (e.g., in deictic environments).
d. Casa and certain kinship terms: raise to D only if followed by a genitive modifier.
e. Normal common nouns: never raise to D.

The access to the derivational strategy required to pick up object reference must be based on some universal version of this scale but can be slightly differently parametrized across languages in the intermediate parts. So, if, at the two extremes, pronouns never occur other than determinerless and in D (cf. Longobardi 1994) and normal common nouns can never achieve object reference, languages may cut the class of raising common nouns in partly idiosyncratic ways: e.g., Catalan is the most productive Romance variety for the raising of casa but shows no comparable behavior with kinship terms; Hebrew displays the relevant peculiarities with kinship nouns, even extending them to a few other relational terms, but not with the word for 'home'. ${ }^{16}$

15. Even a language not exhibiting overt N-to-D like English provides evidence leading to virtually the same hierarchy by inspection of the distribution of overt determiners in argument function: for most nouns of class (25b) occur as singular count arguments without the article, none of class (25e) does, and home, corresponding to casa, does in essentially the same conditions under which casa raises in Romance (cf. Longobardi 1996).

16. Cf. Longobardi (1996); I am indebted to T. Siloni for inspiring suggestions about the Hebrew facts. The combination of several different semantic features could be responsible for the exact position occupied by nominal expressions in the scale (cf. Timberlake 1980). In this sense, Irene Heim (p.c.) suggests that relevant ingredients of the property of casa, mamma etc. distinguishing them from the other common nouns may be their naming a place or a person, typical entities usually referred to by means of a proper name. 
Therefore, a test based just on the ability to access the N-to-D strategy does not reveal a clearcut binary distinction corresponding to the intuitive notions of common nouns and proper names: indeed, the divide between $(25 b)$ and $(25 c-d)$, i. e., the central area of the resulting hierarchy, is apparently the least sharp: they are separated just by the different conditions under which they raise to $\mathrm{D}$. The nouns of $(25 \mathrm{~b})$ raise whenever the possibility arises, the others only under marked circumstances.

However, if the access to the derivational strategy is essentially scalar, another test may help refine our lexical distinctions among nouns and reveal traces of the traditional bipolar contrast.

Thus, an important semantic contrast manifests itself in singular definite phrases. While singular definite arguments built on common nouns may readily achieve a kind-denoting, i.e., generic, interpretation, the latter is straightforwardly impossible for those built on proper names, both with and without the definite article:
a. Il cane è il migliore amico dell'uomo.
'The dog is man's best friend.'
b. La Maria è una brava ragazza.
'The Maria is a good girl.'
c. Maria è una brava ragazza.
'Maria is a good girl.'

Only the subject of (26a) can denote a kind, those of $(26 b-c)$ being confined to the object-referential (so-called specific) reading. Thus, (26) exemplifies a further distinction between head nouns characterizing the constructions with the properties in (3) and those able to characterize the constructions with properties (4).

The contrast in (26) is very suggestive in the perspective of giving a lexical semantic definition of the distinction between the two fundamental types of nouns previously identified on the grounds of properties (3) and (4). Assuming again Carlson's (1977a) ontological partition of individual entities into objects and kinds and applying it, this time, not to the denotation of full argument phrases $\left(\mathrm{X}^{\max }\right.$ but to the intrinsic lexical meaning of single head nouns ( $\mathrm{X}^{\circ}$ items, individual words), let us suppose that nominal words may lexically refer to (or, in other terms, name) either objects or kinds, according to whether they fail or pass the test of kind-denotation provided by the environments of (26). If Carlson is ontologically correct in assuming just two types of individuals, then it will come as no surprise that there are exactly two main types of nouns, object-naming and kind-naming ones. 
The behavior of the nouns of $(25 c-d)$ in singular definite generic constructions suggests instead that they are capable of providing kind-denotation and must not be lexically collapsed with those of (25b):
a. La casa è sempre il bene più ambito dagli italiani. 'The home is still the good most desired by Italians.'
b. Il lunedì è sempre il giorno più impegnativo della settimana. 'The Monday is always the busiest day of the week.'

Then, strictly speaking, we will reserve the term 'proper name' for the object-naming items of (25b) and will call the basically kind-naming ones of $(25 \mathrm{c}-\mathrm{d})$ 'special' or 'raising' common nouns, regarding their objectnaming behavior as an environmentally conditioned shift.

Putting all the evidence together, the four rough classes of nominal heads considered can be so ranked by the three tests:

\begin{tabular}{|c|c|c|c|}
\hline (28) & $\begin{array}{l}\text { object- } \\
\text { referential } \\
\text { (in D) }\end{array}$ & $\begin{array}{l}\text { predicative } \\
\text { restrictions } \\
\text { (not in D) }\end{array}$ & $\begin{array}{l}\text { kind-referential } \\
\text { (with definite article) }\end{array}$ \\
\hline pronouns & + & - & - \\
\hline proper names & + & $\begin{array}{c}+ \\
\text { (conditioned) }\end{array}$ & - \\
\hline $\begin{array}{l}\text { special common } \\
\text { nouns }\end{array}$ & $\begin{array}{c}+ \\
\text { (conditioned) }\end{array}$ & + & + \\
\hline common nouns & - & + & + \\
\hline
\end{tabular}

Prototypical object-naming items (pronouns) are clearly singled apart because they only occur in $\mathrm{D}$ and are unable to function as predicative restrictions to operators, as seems required e. g., in the environments of (19) and, more generally, in definite or indefinite descriptions (cf. section 9 below for clarification); prototypical kind-naming items (normal common nouns) are unable to provide object reference (hence to access $\mathrm{N}$ to-D). The two central classes have conditioned usages which may sometimes apparently draw them closer: non-prototypical object-naming items (proper names) may instead assume kind properties and function predicatively, as in (19), but only under marked conditions to which we return later in section 11; conversely, non-prototypical kind-naming items (those of $(25 \mathrm{c}-\mathrm{d})$ ) are capable of acquiring object reference, but only when complemented with the identifying contextual properties dis- 
cussed above (temporal deixis, genitive restriction approximating them to near unique reference). ${ }^{17}$ Anyway, the kind reading test of (26)-(27) confirms that the major divide runs precisely between these two classes.

\section{BNs as variables}

Let me now review some of the relevant properties (4) of BNs, i.e., determinerless argument phrases with a kind-naming head noun.

(4a) is trivially observable in all modern Romance languages in the same way as, say, in Modern English.

Much more interesting is property (4b). Longobardi (2001), also building on Dobrovie-Sorin \& Laca (1996), has shown in some detail that Romance BNs always display, in the same environments, the same relevant semantic properties (except for scope ${ }^{18}$ ) as overtly indefinite DPs. In particular, they are ungrammatical in exactly those contexts where no indefinite, such as e.g., 'many $\mathrm{Ns}$ ', but only a kind-denoting expression, like e. g., 'that species of objects', is possible. This generalization is sharp and virtually exceptionless. A subset of the relevant environments includes the occurrences of BNs as non-taxonomic subject/object arguments of kind-level predicates, as generic arguments of episodic predicates, as antecedents of kind-anaphoric expressions. ${ }^{19}$ Examples from Longobardi (2001):

a. Elefanti di colore bianco sono estinti.

'White colored elephants have become extinct.' (Only taxonomic, if anything = 'some subspecies of elephants ...')

b. Edison ha inventato lampadine.

'Edison invented bulbs.' (Only taxonomic, if anything = 'some subtypes of bulbs ...')

17. Subtler distinctions intuitively related to the kind- vs. object-naming contrast or to the derivational fact of assuming object reference seem manifested by other morphosyntactic phenomena in other languages, e. g., the phonological alternations hypothesized by Lazzeroni (1995) for a stage of proto-Indoeuropean and perhaps the distribution of articles with so called situative Unika in Ebert's (1970) Frisian dialect and Balearic Catalan varieties (Joan Mascaró, p.c.) or the hierarchy of postnominal possessivization in Scandinavian studied by Holmberg \& Sandström (1996).

18. Chierchia (1998) keenly pointed out the salient resemblance of scope restrictions to the ones noted for English existential BNs in Carlson (1977a, 1977b), even including the occasional suspensions of such constraints in certain environments.

19. Outside Romance a similar pattern of BNs seems to be attested by Greek, Arabic (Fassi Fehri 2003), and probably by Bulgarian (R. Slabakova p.c.) and Hungarian (for which cf. De Swart \& Farkas 2003). 
Elefanti di colore bianco passeranno il Giudizio Universale domani alle 5.

'White colored elephants will undergo the Final Judgement tomorrow at 5.' (Only existential)

(31) Gatti di grandi dimensioni hanno un'alta opinione di se stessi.

'Cats of great size have a high opinion of themselves.' (No 'species' reading for the anaphor)

Therefore, Romance BNs can be safely argued never to refer to the kind named by the head noun. They rather seem to be like quantificational indefinites, understood e.g., à la Kamp (1981) and Heim (1982), i. e., open variables unselectively bound by existential or generic operators made available in the sentential environment or by default assignments. Such variables may then range over objects or kinds (i. e., subspecies, in taxonomic readings). Dobrovie-Sorin \& Laca (1996), Chierchia (1998), and Delfitto (2002) have persuasively drawn attention to the existence of a wider range of possible generic interpretations than considered in previous work on Romance BNs, e.g., Casalegno (1987) and Longobardi $(1991,1994)$. Given the arguments above, however, none of these interpretations must be confused with kind reference proper (DP-internal or referential genericity, in Gerstner \& Krifka's 1987 terms; also cf. Delfitto 2002 on this point). ${ }^{20}$

Further indirect evidence for the quantificational status of Romance BNs comes from Longobardi (2000b), where they are argued to obey some version of Diesing's (1992) Mapping Hypothesis, precisely a condition holding on indefinites, not on referential expressions.

The presence of property (4e) as well, i. e., the lack of the rigid designation typical of names, comes as no surprise, if Romance BNs are not referential expressions.

Because of such conclusions, property (4c) is now best addressed by raising the following question: once Romance BNs are shown to be semantic variables, are they also syntactic variables? By this term one usually refers to actual non-A-bound empty categories, normally left behind by movement and subject to some sort of lexical government require-

20. Coordinated BNs, which, surprisingly, one still sporadically finds used in the literature on such topics, are by no means able to prove anything on reference of BNs. This caveat should already be rather obvious at first inspection, but was also explicitly discussed in Longobardi (1994): coordinated BNs are patently free from virtually all the typical restrictions of Romance BNs (mass/plural, lack of definite specific readings etc. and even occur equally well in French). Much less obvious is a real theory of such BNs, on which now cf. Heycock \& Zamparelli's (2003) and Roodenburg's (2003) comprehensive accounts. Also cf. Zamparelli (1995) suggesting caution even in the use of BNs containing modifiers with indexicals as sources of evidence. 
ment, as in (32b), to distinguish them from pronominal variables such as that in (32a), freer in distribution:

a. Every man knows that he will die (semantic variable).

b. *Which man do you think that _ will leave (syntactic variable).

Unmodified Romance BNs share the restricted distributional pattern of syntactic variables, essentially occurring only in admissible extraction sites for wh-movement. In particular, they are possible in postverbal subject position, in object position, and preverbally only in focused or left-dislocated functions that can supposedly be traced back to a postverbal, lexically governed extraction site. ${ }^{21}$ Crucially, their status is clearly degraded in normal preverbal subject position, in specificational postcopular ('inverse' in Moro's 1997 terminology) position and in many prepositional complement positions (though with some unclear exceptions), all the latter being non-extraction sites in Romance. ${ }^{22}$

Although many points remain obscure about these constraints and their curious suspension under modification, the analogy with the roughly lexically governed (or properly governed, in the sense of Chomsky's 1981 original ECP) distribution of empty categories remains impressive and exact to some fine details, justifying the statement of property $(4 \mathrm{c}) .^{23}$

\section{The Core Generalization}

On these grounds one can finally conceptually make sense of the second generalization proposed in Longobardi (1994), formulated there as a barely typological and intuitive correlation between the syntax/semantics of PNs and BNs: PNs are (object-)referential and subject to N-to-D, BNs cannot be (kind-)referential and cannot undergo N-to-D, as exemplified in (14) above. ${ }^{24}$

21. Again, no confusion must be made between the probative relevance of BNs under modification (adjectives, relative clauses, PPs), which directly affects just their distribution, and that of BNs under coordination, which almost completely liberalizes their interpretations. For some arguably indirect interactions between distribution and interpretation cf. Longobardi (2000b).

22. Cf. Contreras (1986), Torrego (1988), Longobardi (1994, 2000b), among many others, for reference to all these properties.

23. Cf. Delfitto \& Schroten (1991) for further discussion.

24. The generalization could not be formulated in so revealing terms in Longobardi (1994) mainly because that approach failed to recognize that the major divide in the possible interpretations of BNs is precisely between (kind-)referential and quantificational readings, rather than between generic and existential. 
It is thus tempting to strengthen the original biconditional of (15) to (33), the Core Generalization of this domain, unifying both types of constant interpretation, object- and kind-reference, and trying to best capture the original intuition:
a. Reference (to individuals) if N-to-D.
b. N-to-D if reference (to individuals).

The considerations above directly warrant (33b); since we have not found cases of N-to-D with common nouns yet, (33a) will be assumed tacitly until the issue of kind reference can be better discussed and the notion of expletive article introduced. Anyhow, (33) is the abridged formula which best sums up and unifies the insights proposed in Longobardi $(1994,2001)$ : reference, whether to objects or to kinds, is one and the same phenomenon for the computational system of language. (33) is also one of the most striking 'bridging' principles ever uncovered between syntax and semantics of natural language. It states that a particular semantic function is associated with a specific syntactic position, D, rather like scope has been argued especially by May $(1977,1985)$ and Huang (1982) to be associated with certain A'-positions. If correct, this is the type of discoveries which should substantiate a research program connecting syntax and semantics such as advocated e.g., in Delfitto (2003).

\section{Non-arguments}

Notice now that properties (4a, b and c) attributed above to Romance BNs hold obligatorily of them only if they occur in argument function; for in non-argument function all Romance nouns may in principle occur determinerless without necessarily being mass/plural, indefinite and lexically governed:
a. Presidente, venga qui!
'President, come here!'
b. Maledetto maiale!
'Damn' pig/pork!'
c. Giustizia è fatta!
'Justice has been done!'

Vocatives (34a) have been proposed to have a special status, which could exempt them anyway from the argument-position constraints via a different mechanism (cf. Crisma 1997). But predicates abundantly support the point, in addition to exclamations and idioms (34b, c). For example, 
(35a) exhibits the suspension of the mass constraint on singulars; the contrast between the perfectly natural (35b), with a predicative bare plural, and (35c), with an argument bare plural, witnesses the suspension of the obligatory indefiniteness: (35c) is infelicitous with the consuls (and not with the senators), because we know that there were just two per year and the presupposition of maximality would require a definite interpretation, impossible in argument position:

a. È / Si è mascherato da presidente della Repubblica. 'He is / He disguised himself as president of the Republic.'

b. Bruto e Collatino furono consoli della repubblica romana nell'anno 509.

'Brutus and Collatinus were consuls of the Roman republic in the year 509.'

c. Questo ritratto di due personaggi in toga raffigura senatori / $(\%)$ consoli della repubblica romana nell'anno 509.

'This portrait of two characters in a toga features senators / consuls of the Roman republic in the year 509.'

Furthermore, non-argument determinerless common nouns are regularly possible in the Romance language which does not admit of normal BNs, namely modern French.

Now, properties ( $4 \mathrm{a}, \mathrm{b}$ and $\mathrm{c}$ ) could be viewed as necessary manifestations of an empty category occupying the D position: especially convincing evidence for the theory that an empty D characterizes Romance BNs has been, since Contreras (1986) first proposed it, the property in (4c), given the observation discussed in section 5 that the distribution of Romance BNs coincides exactly with that of empty categories left behind by movement and traditionally subject to some version of Chomsky's (1981) ECP (also cf. some analogy with Stowell's 1981 proposals about empty C).

The other two properties do not provide as compelling (and relatively theory-neutral) evidence for an empty $\mathrm{D}$, but at least can be reduced well to those of such a category, under natural assumptions, a version of which will be outlined in section 11. In particular, the idea that mass/ plural, but not singular count nouns pattern as if they followed a phonetically invisible D seems empirically suggested by some other non-argument environments where bare mass/plurals behave like overt DPs and unlike bare singulars.

Just for one example, consider the status of predicative phrases modified by a restrictive relative clause:

a. Gianni è medico.

'Gianni is doctor.' 
b. Gianni è un medico.

'Gianni is a doctor.'

c. *Gianni è medico che si cura davvero dei suoi pazienti.

'Gianni is doctor who really cares for his patients.'

d. *Gianni è medico che / quale tutti vorrebbero essere.

'Gianni is doctor that / which everyone would like to be.'

As a predicate, a bare count singular may often function perfectly well, but, unlike overt DPs, cannot head a restrictive relative clause, even one with a clearly predicative wh-phrase.
a. Gianni è un medico che si cura davvero dei suoi pazienti.
'Gianni is a doctor who really cares for his patients.'
b. Gianni è il medico che tutti vorrebbero essere.
'Gianni is the doctor that everyone would like to be.'
c. Gianni è un campione quale tutti vorrebbero essere.
'Gianni is a champion which everyone would like to be.'

Theoretically, this is not unexpected indeed given an assumption made by a long and renewed tradition of scholarship on relative clauses: ${ }^{25}$

$$
\text { Restrictive relative clauses are necessarily complements to D }
$$

But plurals and mass nouns can head such clauses:

(39) a. Noi siamo medici che ci curiamo davvero dei nostri pazienti.

'We are doctors who really care for our patients.'

b. Quelli sono campioni quali tutti vorrebbero essere. 'They are champions which everyone would like to be.'

c. Noi siamo dei medici che ci curiamo davvero dei nostri pazienti.

'We are partit. art. doctors who really care for our patients.'

d. Quelli sono dei campioni quali tutti vorrebbero essere.

'They are partit. art. champions which everyone would like to be.'

a. Questa è acqua.

'This is water.'

25. Cf. Smith (1964), Chomsky (1965), and now Kayne (1994, 2003), Bianchi (1999), building on Vergnaud (1974). 
b. Questa è dell'acqua.

'This is partit. art. water.'

c. Questa è acqua che è stata presa dalla sorgente.

'This is water which was taken from the spring.'

d. 'Questa è dell'acqua che è stata presa dalla sorgente.

'This is partit. art. water which was taken from the spring.'

The conclusion is that with restrictive relatives mass/plurals pattern with overtly determined, not with bare singular predicates. ${ }^{26}$

Let us tentatively suppose, then, that mass/plurals, unlike singulars, can be introduced by an empty determiner. A more principled account of this asymmetry will be presented in section 11 .

On these premises, then, a D category, supposedly held responsible for (4a, b and c), may be assumed to be necessary for argument (and certain non-argument) nominals, but often dispensable in various other non-argument functions, lending support to a generalization first proposed by Szabolcsi $(1987,1994)$, Stowell $(1989,1991)$ and particularly discussed in Crisma (1999), all on non-Romance evidence:
A 'nominal expression' is an argument only if it is introduced by a category D.

In the case of determinerless common nouns, thus, assuming (41) may suffice to account for the contrast of argument and non-argument instances with respect to properties (4a, b and c).

One may wonder whether the same generalization is mirrored in the behavior of determinerless proper names, namely whether the obligatoriness of the $\mathrm{N}$-initial order disappears exactly with those nominals, i. e., non-arguments, like predicates, vocatives or exclamations, which,

26. Correspondingly, in secondary predication environments prohibiting the occurrence of determiners altogether, even mass/plurals fail to occur restricted by a relative clause:

(i) a. Figlio di professori, Mario è sempre stato molto versato negli studi.

'Son of professors, Mario has always been very inclined to study.'

b. *II/Un figlio di professori, Mario ...

'The/A son of professors, Mario ...'

c. *Figlio di professori che vuole imitare i genitori, Mario ...

'Son of professors who wants to imitate his parents, Mario ...'

(ii) a. Figli di un generale, Mario e Paolo desiderano soltanto la gloria militare. 'Sons of a general, Mario and Paolo only strive for military glory.'

b. *I/Dei figli di un generale, Mario e Paolo ... 'The/Some sons of a general, Mario and Paolo ...'

c. *Figli di un generale che vogliono imitare il padre, Mario e Paolo ...

'Sons of a general who want to imitate their father, Mario and Paolo ...' 
under (41), may be argued to be often realized without involving a D position. ${ }^{27}$ The expectation is straightforwardly borne out:

(42) Romeo si è travestito da vecchio Capuleti, per entrare nel palazzo e vedere Giulietta.

'Romeo disguised himself as old Capuleti, in order to get into the palace and see Juliet.' ${ }^{28}$
a. Mio caro Gianni, vieni qui!
'My dear Gianni, come here!'
b. Gianni mio caro, vieni qui!
'Gianni my dear, come here!'
a. Mio Dio!
'My God!'
b. Dio mio!
'God my!'

Clearly both orders are possible in such examples. This means that the properties of BNs and PNs with respect to the argument/non-argument distinction are parallel: bare proper names are exempt from the obligatoriness of raising precisely in those environments where bare common nouns are exempt from the three restrictions reduced before to the presence of an empty D. The generalizations can be summed up in the following table:

\begin{tabular}{|c|c|c|}
\hline (45) & Arguments & Non-arguments \\
\hline $\begin{array}{l}\text { Bare proper } \\
\text { names }\end{array}$ & + obligatory raising & - obligatory raising \\
\hline $\begin{array}{l}\text { Bare common } \\
\text { nouns }\end{array}$ & $\begin{array}{l}\text { + obligatorily indefinite } \\
\text { + obligatorily mass/plural } \\
\text { + obligatorily lex. governed }\end{array}$ & $\begin{array}{l}\text { - obligatorily indefinite } \\
\text { - obligatorily mass/plural } \\
\text { - obligatorily lex. governed }\end{array}$ \\
\hline
\end{tabular}

The convergence of the two asymmetries, emerging from quite distinct domains but singling out the same diagnostic environments (argument/nonargument), turns out as the strongest argument ever for a principle like (41),

27. With the reservations above for vocatives (cf. Crisma 1997).

28. The epithets of fn. 9 above pattern analogously:

(i) Si è travestito da bambino Gesù / Vergine Maria.

'He disguised himself as baby Jesus / Virgin Mary.' 
which is then very well supported at least in Romance. For there is some evidence for the presence of a $\mathrm{D}$ in argument function in either case, in one construction remaining phonologically empty and thus subject to a lexically governed distribution (akin to that of all non-pronominal empty categories), in the other being derivationally filled by the raised $\mathrm{N}$.

\section{Expletive articles}

As noticed above, in several Romance varieties many nouns of the class (25b) occur introduced by an article, normally of the definite type, though displaying exactly the properties listed in (3) (but, of course, not the N-to-D raising), which are normally not shared by definite descriptions. Thus, (46) is semantically virtually identical with (5), while the embedded subject of (47) does not display the same wide scope and rigidity properties:

Non credo che la Maria verrà.

'I don't believe that the Maria will come.'

Non credo che la mia vicina di casa verrà.

'I don't believe that my neighbor will come.'

We have also seen above how the article with such names is unable to induce the kind-denoting (generic) reading possible with definite singular common nouns. These facts suggest that the article of such constructions does not play any autonomous semantic function: it may well be a 'placeholder' for the name in the absence of N-to-D raising. Since Longobardi (1991, 1994), it has been sometimes regarded as an expletive article (a notion elaborated in a slightly different context by Vergnaud \& Zubizarreta 1992), forming with the name below a CHAIN (in Chomsky's 1986 sense) which alternates with the regular antecedent-trace chain of, say, (5).

In a normal definite description, instead, the article has a semantic content of its own, probably functioning as a variable-binding operator, with the noun using its kind-naming properties to provide a predicate restricting the range of the variable (cf. section 10 for more details).

In addition to these purely semantic considerations, the expletive hypothesis for such articles is independently supported by scattered pieces of morphological (Catalan, Frisian) and syntactic (coordination properties) evidence distinguishing certain articles used with proper names from other instances.

Thus, many varieties of Catalan morphologically distinguish between two types of 'definite' article, one which is exclusively used with personal proper names, masc. en / (rarer) fem. na, and another one, el / la, employed in all other circumstances, i. e., with common nouns in the specific and ge- 
neric readings and with non-personal proper names. This fact gives rise to patterns like the following:
a. el gos
'the dog'
b. en Pere
'the Peter'

In our framework this suggests that at least one subcase of what we identify as the expletive article introducing proper names surfaces as morphologically distinct from the regular definite article. Given the intrinsic singularity which is required for the referential interpretation of proper names (cf. (3a)), the prediction ensues from our analysis of the Catalan article that the same proper names that take the expletive article en in the singular will have to resort to the regular article els if used in the plural. The prediction is correct:

$$
\begin{aligned}
& \text { a. } \quad \text { *ens (dos) Peres } \\
& \text { 'the expl. (two) Peters' } \\
& \text { b. els (dos) Peres } \\
& \text { 'the (two) Peters' }
\end{aligned}
$$

An analogous prediction arises and is correctly borne out in the case of restrictive relative modification of proper names; such structures must in fact resume the regular definite article and exactly parallel the 'common noun' behavior of Italian names exemplified in $(19 a-b)$, once we replace raising by the expletive in the b. example:
a. El Joan que coneixia ja no existeix.
'The Joan that I used to know no longer exists.'
b. *En Joan que coneixia ja no existeix.
'The (expl.) that I used to know no longer exists.'

A similar, but wider, usage of a putative expletive article may be instantiated by the Frisian dialect of Föhr, at least according to a plausible, though by no means uncontroversial, interpretation of Ebert's (1970) generalizations (cf. Longobardi 1994).

Finally, there is also a piece of syntactic evidence. While many varieties admit or require the definite article with certain proper names, coordination of two NPs, one headed by an unmodified proper name and the other by a common noun, excluding the definite article, turns out to be sharply impossible in all dialects:

$$
\text { * La Maria e (mia) segretaria è arrivata in ritardo. }
$$

'The Maria and (my) secretary arrived late.' 
The otherwise surprising ungrammaticality of this coordination can be immediately explained by the assumption that the two NPs do not meet the requirement of identity in interpretation which seems to be necessary for coordination: in fact, segretaria is likely to be a kind-predicate instantiating a range for the definite article understood as a real operator, whereas Maria is an object-referring noun linked in a CHAIN to the article functioning as an expletive. ${ }^{29}$

The data in (46) and (51) suggest an even stronger conclusion, namely that a singular proper name unmodified and introduced by the definite article, like e. g., la Maria, always behaves object-referentially (i. e., with the article understood as an expletive, not an operator): in other words it is not ambiguous, as one could perhaps expect, between giving rise to a $\mathrm{PN}$ or to a definite description. This conclusion joins, and falls together with, that drawn from (26b) above. The obligatorily expletive function of the article appears to be a consequence of the marked nature of any kind-naming interpretation for basically object-naming expressions like proper names, to be better discussed below in section 11.30

Here it is important to remark that the term $N$-to- $D$ in the generalizations (15) above must be understood as comprising two equivalent subcases, either a chain or a CHAIN between $\mathrm{N}$ and the $\mathrm{D}$ position.

The introduction of the concept of expletive article for proper names as head of a CHAIN allowed Longobardi (1994) to adopt and extend an independent proposal by Vergnaud \& Zubizarreta (1992) that the definite article introducing singular generics is actually an expletive, thus satisfying even

29. It should be less ungrammatical to coordinate a common noun with a proper name clearly used as a predicative expression providing the quantificational range to a nonexpletive article. This is only possible with restrictively modified names. Though quite marginal and emphatic, some coordinations like the following, appearing to fulfill the prediction, were pointed out in Longobardi (1994):

(i) ?Il Dante della Commedia e massimo poeta italiano non è sempre facilmente riconoscibile nei versi della Vita nova.

'The Dante of the Commedia and greatest Italian poet is not always easily recognizable in the poems of the Vita Nova.'

30. The occurrence of such supposed expletive articles allows one to postulate finer distinctions in the hierarchy (25). In fact, among the proper names of (25b) there are some which refuse expletive articles, always resorting to $\mathrm{N}-$ to-D, and others which require them. Languages exhibit a good deal of variation in this domain, but certain rough subgeneralizations begin to emerge: there are cases where subclasses of proper names internally behave rather uniformly, but if e. g., an asymmetry occurs among geographical names in a certain variety, it seems to be the case that names of more 'atomic' entities like cities (and so called 'small' islands in a culturally non-trivial sense: cf. Longobardi 1987, 1997) undergo N-to-D, while names of 'extensive' or 'bidimensional' areas, like countries and regions, resort to the expletive (e. g., cf. Italian and French); if an asymmetry occurs among personal names, the situation is always such that names of females use the expletive and names of males raise to D. 
the extended N-to-D requirement for kind reference proposed in (33). For such phrases behave as kind names (referential generics, in Gerstner \& Krifka's 1987 spirit), perfectly surviving in all the diagnostic environments mentioned in section 5 above, i. e., as arguments of kind-level predicates, as generic arguments of episodic predicates, as antecedents of kind-anaphoric expressions. Since at least these properties hold in the same way of definite mass/plural generics of Romance (e. g., cf. Longobardi 2001), despite of some differences with the singular ones, it is possible that their definite articles are equally expletive (Longobardi 1994). ${ }^{31}$ Anyway, the possible existence of kind-referential nominals in Romance is perfectly reconciled, by means of expletive articles, with generalization (33). Hence, expletive articles help establish (33) as the crucial unifying property of all Romance nominals not introduced by an overt quantifier.

\section{The Topological Mapping Theory}

After reviewing disparate sources of evidence, we are now in a position to address the issue of a general theory of nominal denotation, mapping syntactic forms onto logically oriented representations. A priori one would like for such a theory to be comprehensive, explanatory and parametric. Comprehensive, since it should hopefully encompass the behavior of PNs, BNs, and overtly determined descriptions; explanatory, to account in a principled way for the differences between these categories, simply stipulated in previous references like Longobardi (1994); parametric, i. e., flexible enough to potentially accommodate the crosslinguistic superficial differences arising in this domain. The latter point is beyond the scope of the present paper and will be discussed in future work; I will concentrate here to meet the first two standards.

We noticed that Romance PNs acquire object reference via N-to-D raising. This way they escape the constraints holding instead on BNs (some version of Chomsky's (1981) ECP, imposing lexical government and the interpretation as a variable). How precisely is this so?

Let me propose a principle like (52) which, along with a licensing condition such as (53), constitutes a mapping theory for nominal interpretation:

Denotation Hypothesis: Individuals are denoted in D.

Licensing condition: Arguments denote individuals.

31. However, a recent interesting proposal by Dayal (2003) suggests that definite articles in generic phrases may introduce taxonomic expressions (i. e., be real definite operators whose variables range over subkinds). 
First of all, notice that the conjunction of (52) - (53) immediately derives (41) as a theorem, i. e., Szabolcsi's and Stowell's generalization that we have seen to be empirically strongly supported in Romance.

Now, by 'virtual conceptual necessity' individuals can be denoted as constants (referentially single-valued expressions) or as variables (which have a set of referential values, potentially ranging from zero to infinite). Then, (52) means that an argument will denote as a constant or a variable according to the content of its D. Let us consider the following most natural definitions:

a. Constants have a fixed referential value denoting one and only one entity (kind or object).

b. Variables are bound by (coindexed with) an operator and range over a set of entities (kinds - for taxonomic readings or objects).

Therefore, constant interpretation will normally require a chain/CHAIN link between a (kind- or object-naming) $\mathrm{N}$ and $\mathrm{D} ;{ }^{32}$ otherwise we will obtain a variable interpretation. Hence, (52) in conjunction with (54a) will also yield (55) as a theorem:

Arguments with empty D are variables.

Thus, this framework accounts neatly for the interpretation of PNs, BNs and of constructions with expletive articles, making exclusive reference to their structural position in the DP ('topological' mapping theory ${ }^{33}$ ).

The other obvious theorem of (52)-(54) states that Ds occupied by an overt category other than one having (or CHAIN-linked to) referential content, i. e., Ds occupied by a lexical determiner or quantifier, will be equally translated into a variable. This too seems a welcome result, extending the account to the interpretation of many definite and indefinite descriptions and quantified expressions.

Now, binding of the variable may be ensured unselectively (empty D of BNs, bound by Ex or Gen operators; cf. Longobardi 2001 among others) or selectively by the very operator overtly present in $\mathrm{D}$, which may be taken to automatically share an index with its projections. The two subcases might fall together even more clearly at a further level of representation under Dobrovie-Sorin's (1994) Discourse Representation, LF-raising the operator

32. Further candidates for playing a referential function in D are demonstratives, given their causal affinity to proper names outlined e. g., in Kaplan (1978).

33. Theories in this spirit dealing with further aspects of nominal interpretation have been presented e. g., by Zamparelli (1995) and Vangsnes (2000). 
and derivationally creating an actual empty category in $\mathrm{D}$, though I will not pursue the details of this analysis here. ${ }^{34}$

To sum up, the content of the Topological Mapping Theory (52)-(54) is best expressed by its most perspicuous theorem, (56), which, under the assumed definitions, is equivalent to the Core Generalization (33):
a. An argument is a constant only if $\mathrm{D}$ contains $\alpha, \alpha$ a lexically referential expression. ${ }^{35}$
b. Otherwise: An argument is a variable.

\section{Why are Bare Nouns and Proper Names different?}

Then, the axioms (52) and (53) correctly predict the semantics of Romance determinerless arguments from their observable positional syntax: BNs, which do not undergo raising, will be subject to a variable interpretation. Kind reference, thus, is correctly predicted to be achieved, if at all, only by means of expletive articles, i. e., of a CHAIN, not a chain. Conversely, PNs gain object reference through either a chain or a CHAIN, thus deriving one part of (15) (i. e., if object-reference then N-to-D), and are actually obliged to do so. Which principles, now, yield precisely this syntactic state of affairs, i. e., force Romance argument determinerless proper names, but do not even allow common nouns, to raise to $\mathrm{D}$ ?

As appropriately noticed in Longobardi (1996) and Chierchia (1998), this crucial problem was only stipulatively dealt with in Longobardi (1994): in terms of the economy of the feature system adopted there, the opposite could have well been the case at the same cost. The issue certainly requires a more explanatory solution: for, to my knowledge, no language has ever been discovered exhibiting the opposite configuration (determinerless common nouns, but not proper names, raising to D). ${ }^{36}$

Let us then factor out the problem into three questions: ${ }^{37}$
a. Why do common nouns not have to raise to $\mathrm{D}$ ?
b. Why are common nouns not even allowed to raise to D (cf. (14b) above)?
c. Why must Romance proper names raise to D?

\footnotetext{
34. I am very much indebted to B. Laca, S. Rothstein and D. Delfitto for inspiring suggestions on this point, at different moments of elaboration of these ideas.

35. I.e. an actual noun, pronoun or demonstrative (or equivalently an expletive article linked to the noun in a CHAIN).

36. Outside Romance, a possible instance of N-to-D movement for proper names has been suggested, on subtler evidence, to exist in Igbo by Déchaine \& Manfredi (1998).

37. The guidelines of the present solution were first worked out in Longobardi (1996).
} 
Consider, to begin, that another theorem of (52) states that nouns not linked with D in a chain/CHAIN can only project property- (not individual-)denoting expressions; therefore, in conjunction with essentially any version of the Full Interpretation Principle, (52) predicts that they can only survive as predicates. In particular, let me suppose that whenever $\mathrm{D}$ is translated into a variable, for the latter to meet (54b) the noun must function as a kind predicate. ${ }^{38}$ For, variables must range over (members of) a set and objects (the other type of assumed entity) are not sets by definition: they cannot be decomposed into further natural subentities or arbitrary subquantities all nameable that way (otherwise they would automatically be count or mass kinds).

For concreteness, let us consider how this approach may technically work: an argument of the surface form

$$
[\mathrm{D}[\mathrm{N}]] \text { (where } \mathrm{D} \text { is an overt operator) }
$$

will be roughly translated into the logical form

$$
\text { Dx, such that } \mathrm{x} \text { belongs to the kind named by } \mathrm{N}
$$

so that e. g., (60a) will be translated as (60b) and (61a) as (61b):
a. il/ogni ... tavolo
'the/every ... table'
b. $\quad 1 / \forall x$, such that $x$ belongs to the kind 'tables'
a. molti tavoli / molta acqua 'many tables / much water'
b. many $x$, such that $\mathrm{x}$ belongs to the kind 'tables'/'water'

As is known, some singular determiners select a count, others a mass interpretation, while plurality always implies countability. To provide such a unitary translation as (61b) to (61a), we can thus assume the definition (62):

38. The explanatory apparatus proposed here predicts that this predicative function of nonraised nouns may also co-occur with a referential interpretation of the argument, if independent referential content may occupy D. This is likely to be precisely the case with demonstratives and pronouns in simple cases like the following:

(i) a. noi linguisti

'we linguists'

b. questo libro (qui)

'this book (here)' 
(62) x ranges over natural individuals with count determiners, over arbitrary units of measure for the size of subquantities with mass determiners.

The same will be true for an unselectively bound variable, i. e., for an empty D. Indeed, this apparatus allows us to incorporate Longobardi's (1994) solution for the systematically determiner-like behavior of mass/plurals: the proposal is that the canonical expression of kind naming is morphologically plural if and only if the kind is + count (countable kinds, as opposed to mass ones, encode the idea that one can count several naturally given tokens of the same type). The morphological singularity of table in count expressions like e. g., 'the/every/a/some table' would be nothing but surface uninterpretable agreement of the noun with the singular number of the determiner, the latter an interpretable feature, sometimes (i. e., according to the specific lexical determiner) meaning 'singular denotation', sometimes not (cf. Italian qualche 'some', nessun 'no'). Since empty D is not a lexical item, i. e. has no selectional properties of its own, its restriction will name a kind 'purely', i. e., will be plural if count, singular if mass. This accounts for the observations of section 7 above.

Let us return now to the questions (57). If kind naming is a defining characteristic of common nouns, as argued in section 4, the latter will always be able to satisfy the conjunction of (52)-(54b), by entering formulas like (59), thus even to follow an empty $\mathrm{D}$. Therefore, they need not raise from $\mathrm{N}$ to D. This answers (57a). Now, since Chomsky (1995), one economy condition has become standard, in one formulation or other:

Move only if it is a Last Resort for convergence (i. e., to obtain a grammatical output).

This very consideration answers (57b): since common nouns are kind-naming expressions, hence can restrict a variable anyway, there are no convergence purposes for movement to take place (movement would not be a Last Resort). In simpler words, (14b) above is ungrammatical because (14a) is perfectly well formed.

Instead, the fact that object-naming nouns, essentially proper names, ${ }^{39}$ undergo obligatory raising to an empty $\mathrm{D}$ must precisely be derived as a consequence of their being object- and not kind-naming.

We have independently seen that proper names fail a kind-referential reading as such, as in examples (26) above. This is not surprising under a causal approach: learning a proper name means learning how to apply it to

39. But also casa and lunedì under the special conditions sketched above. 
a particular object, a unique term of experience, unlike learning a common noun, which supposes a potentially open set of so-named objects recognizable as such (a kind).

This does not mean that object-naming is not a property, i. e., cannot be used in predicative contexts; indeed it can, as e. g., in:

$$
\begin{aligned}
& \text { Se io fossi Maria ...' } \\
& \text { 'If I were Maria ...' }
\end{aligned}
$$

(64) is an object predicate, it means something like 'if I had the property of being that specific Maria', not just '.. of belonging to a (potentially open) set of people named Maria'. But this is not sufficient for a variable: restricted by a proper name in this sense, it would crucially fail (54b), not ranging over a set of entities.

Proper names will therefore have to eliminate the variable, to avoid nonconvergence by (54b). This, in turn, means raising to fill the empty $\mathrm{D}$ with referential content. Thus, they must raise for convergence purposes, hence by Last Resort they can raise. $Q E D$.

\section{Proper names and type shifting}

To sum up, we solved the puzzle of an explanatory account of N-raising by concluding that *[DP $\mathrm{N}_{\text {kind } \ldots t} \ldots t$ is impossible because [DP $e \ldots \mathrm{N}_{\text {kind }}$ ] is independently possible, and vice versa [DP $\left.\mathrm{N}_{\text {object }} \ldots t\right]$ is possible because $*[\mathrm{DP} e$ $\ldots \mathrm{N}_{\text {object }}$ is independently impossible.

It could be objected to the proposed solution, however, that the same lexical items recognized as proper names above may occasionally function like regular common nouns:
a. Ogni Maria in questa aula ... / Quella Roma che conoscevi tu ...
'Every Maria in this classroom ...'/'That Rome that you used to know ...'
b. Ho trovato Marie dappertutto.
'I found Marias all over the place.'
c. Le Marie di solito sono brave ragazze.
'Marias are usually good girls.'
d. Se fossi una Maria ...
'If I were a Maria ...'

These examples sound marked but acceptable. All such occurrences seem to have shifted precisely to a kind interpretation: for example, the variable of (65a and b) ranges over different entities thus named. Why couldn't this happen with a singular determinerless proper name? 
In the previous cases, the kinds are all countable (sets of individuals named that way). With an empty determiner we should expect shifted proper names to designate mass kinds (sets of arbitrary sizeable subquantities named that way). This kind of shift is definitely marginal, though not absolutely impossible, if a lexical determiner requires it:

a. ?Hanno messo più antica Roma in questo film che in tutti i precedenti.

'They put more ancient Rome in this movie than in all the previous ones.'

b. ?Parecchia Francia di destra e di sinistra temeva Léon Blum più di Hitler.

'Much right- and left-wing France feared Léon Blum more than Hitler.'

c. ?Napoleone conquistava ogni settimana troppa Russia per poterla tenere sotto controllo.

'Napoleon was conquering too much Russia every week to be able to keep it under control.'

This constraint alone, whatever it means, seems unlikely to suffice to account for the obligatoriness of N-to-D in all the relevant cases, given that the failure of the latter produces extremely sharp results, as we know. Just to repeat the point, consider:

a. Hanno assegnato territorio tedesco a ciascuna delle potenze vincitrici.

'They assigned German land to each of the victorious powers.'

b. *Hanno assegnato Germania / vecchia Berlino a ciascuna delle potenze vincitrici.

'They assigned Germany / old Berlin to each of the victorious powers.'

c. Hanno assegnato Berlino a ciascuna delle potenze vincitrici. 'They assigned Berlin to each of the victorious powers.'

(67b), minimally contrasting with the case of a common noun in (67a), is anyway far more unacceptable than any of the admittedly marginal (66), and Berlino in (67c) can only be interpreted as object-referential (despite of the improbable semantics ensuing for the whole sentence, which contains a distributive universal quantifier), i. e., as raised to D. ${ }^{40}$

40. Germania is straightly ungrammatical in (67b), rather than just being object-referential like Berlino in $(67 \mathrm{c})$, because, as a country name, it obligatorily requires the expletive article in Italian, rather than overtly raising. 
The possibility of type-shifting to a kind interpretation is subject to significant restrictions, though. Crucially, it fails for phrases simply formed by the definite article and a singular unmodified proper name (e. g., la Maria), as can be argued from two facts: their failure to function generically (i. e., as kind-denoting; cf. section 4) and to behave semantically and syntactically (coordination) like true definite descriptions (cf. section 8). This limitation seems to be of a pragmatic-functional nature; it tends to fade away whenever some lexical material is added forcing the kind reading:

a. Gianni vorrebbe sposare la Maria che abita più vicino a casa sua.

'Gianni would like to marry the Maria who lives closest to his home.'

b. La tipica Maria si veste da brava ragazza. 'The typical Maria dresses as a good girl.'

The addition of a restrictive relative immediately allows a de dicto and nonrigid reading and that of the kind-level adjective 'typical' restores a generic interpretation. The 'functional' patterning of this condition seems to reveal the markedness of the type-shifting operation, possible only under extreme conditions: the most obvious seems the need to save the interpretability of other elements of the DP; this was actually the case in all the examples of (65)-(66). Overt elements which would be uninterpretable without a kind reading of the noun are the plural morpheme (since objects are intrinsically singular), a determiner other than a definite article and certain restrictive modifiers (since they require a variable). ${ }^{41}$ The definite article, instead, being ambiguous between an expletive and an operator interpretation, is unable to trigger this effect.

The usage of a type-shifted name, then, is far from free; the fact that it cannot be used to avoid raising a singular determinerless name can now be understood if one supposes that the functional motivation of the operation does not care about grammaticality per se: it could not rescue a crashing derivation (only movement acts as a syntactic Last Resort in this sense), but would only be triggered (superimposed) by the interpretive requirements of

41. Thus, the kind-naming interpretation emerges again with a singular proper name introduced by the indefinite article, since the latter cannot be understood as an expletive but just as a lexical operator, giving rise, in the appropriate environments, to indefinite readings both generic and specific:

(i) a. Una Maria di solito è una brava ragazza.

'A Mary is usually a good girl.'

b. Gianni ha sposato una (certa) Maria.

'Gianni married a (certain) Maria.' 
some overt element of the DP. Type shifting, and shifting to a mass reading even more so, would be a device to avoid violating a pragmatic maxim like 'Do not merge eventually uninterpretable lexical material'. ${ }^{42}$ No wonder, then, that such a non-lexical element as an empty D, which seems to anyway display no selectional properties more generally cannot trigger type shifting.

Therefore when an empty $\mathrm{D}$ is present, the only alternative for a proper name remains filling it through $\mathrm{N}$-to- $\mathrm{D}$, creating an object-referential argument.

Supported by these independent considerations, then, a nominal mapping theory armed with (52)-(53)-(54) and coupled with a standard economy approach to movement is able to provide a principled answer to the question of the raising asymmetry between proper names and common nouns with its far-reaching consequences.

\section{Crosslinguistic consequences}

I will conclude by recasting in the terms of this approach a parametric consequence which already descended from the core pair of generalizations originally proposed in Longobardi $(1991,1994)$ and now subsumed under (33).

Recall that, in the present framework, PNs are supposed to circumvent some typical restrictions observed by BNs, in particular the indefinite interpretation and the lexically governed distribution as an effect of N-to-D raising. In other words, UG would establish some intrinsic connection between (15) and the fact that BNs exhibit the properties in $(4 b-c)$ : the original intuition has finally been more formally understood and captured by generalizing (15) into (33). Now, the typological prediction follows that if a language does not observe (15), at least in its overt syntax, then we may expect it not to observe (33) altogether, thus its BNs not necessarily to exhibit all the properties in (4), in particular $(4 b-c)$. Thus, if neither overt N-to-D nor an expletive article are required for object-reference, then in the framework sketched in (56) they shall not be required for reference tout court, opening the way to kind-referential (non-indefinite) BNs, impossible in Romance.

This expectation is borne out in the contrast of Italian (and much of Romance and at least Greek) with English (and much of Germanic): in English, proper names do not overtly raise to D (cf. 'Ancient Rome was a large city') and, correspondingly BNs can occur lexically ungoverned and with kindreference (referential generics as in 'Dinosaurs have become extinct': cf. Longobardi 2001 and section 4 above). This topic has begun to be the sub-

42. Whether it is shifting to a kind reading by itself or shifting to a mass kind reading in particular (or both) which is so constrained (and ultimately responsible for raising proper names) will have to be decided also on the grounds of further typological evidence (e. g., proper names in languages displaying bare count singulars etc.). 
ject of some lively investigation since it was first put on the research agenda in Longobardi (1991), but seems to still deserve further empirical consideration; ${ }^{43}$ however the apparent correctness of this crosslinguistic prediction, at a time affecting both BNs and PNs, already reinforces in a decisive way the unified approach to the theory of object- and kind-reference defended here.

Received: 28 January 2004

Dipartimento di Scienze

Revised version received:

14 December 2004

Geografiche e Storiche

Università di Trieste

\section{References}

Abney, Steven (1987). The English Noun Phrase in its Sentential Aspect. Unpublished Ph.D. dissertation, MIT.

Bernstein, Judy (1992). On the syntactic status of adjectives in romance. CUNY Forum 17: $105-122$.

Bernstein, Judy (1993). Topics in the syntax of nominal structure across Romance. Unpublished Ph.D. dissertation, CUNY.

Bianchi, Valentina (1999). Consequences of Antisymmetry: Headed Relative Clauses. (Studies in Generative Grammar, 46) Berlin/New York: Mouton de Gruyter.

Burge, Tyler (1973). Reference and proper names. The Journal of Philosophy 70: 425-439.

Carlson, Greg (1977a). Reference to kinds in English. Ph.D. dissertation, University of Massachusetts at Amherst; now New York: Garland (1980).

Carlson, Greg (1977b). A unified analysis of the English bare plural. Linguistics and Philosophy 1: 413-456.

Casalegno, Paolo (1987). Sulla logica dei plurali. Teoria 2: 125-143.

Chierchia, Gennaro (1998). Reference to kinds across languages. Natural Language Semantics 6: $339-405$.

Chomsky, Noam (1965). Aspects of the Theory of Syntax. Cambridge: MIT Press.

Chomsky, Noam (1981). Lectures on Government and Binding. The Pisa Lectures. (Studies in Generative Grammar, 9) Dordrecht: Foris.

Chomsky, Noam (1986). Knowledge of Language. Its Nature, Origin, and Use. (Convergence) New York: Praeger.

Chomsky, Noam (1995). The Minimalist Program. (Current Studies in Linguistic Series, 28) Cambridge: The MIT Press.

Contreras, Heles (1986). Spanish bare NPs an the ECP. In Generative Studies in Spanish Syntax. (Studies in Generative Grammar, 27) Ivonne Bordelois, Heles Contreras \& Karen Zagona (eds.), 25-49. Dordrecht: Foris.

Crisma, Paola (1991). Functional categories in the NP: a study of the distribution of nominal modifiers. Tesi di laurea, Università di Venezia.

Crisma, Paola (1996). On the configurational nature of adjectival modification. In Grammatical Theory and Romance Languages. Selected Papers from the 25th Linguistic Symposium on Romance Languages (LSRL XXV). Seattle, 2-4 March 1995. (Amsterdam Studies in the Theory and History of Language Science, Series 4 - Current Issues in Linguistic Theory, 133) Karen Zagona (ed.), 59-71. Amsterdam: Benjamins.

43. At least cf. the final sections of Longobardi $(1996,2001)$ for the preliminary outline of one parametric approach, and Chierchia (1998) and Crisma (1999) for further proposals and discussion. 
Crisma, Paola (1997). L'articolo nella prosa inglese antica e la teoria degli articoli nulli. Unpublished Ph.D. disertation, Università di Padova.

Crisma, Paola (1999). Nominals without the article in the Germanic languages. Rivista di Grammatica Generativa 24: 105-125.

Dayal, Veneeta (2003). Genericity and (in)definiteness: a cross-linguistic study. Unpublished manuscript, Rutgers University.

Déchaine, Rose-Marie \& Victor Manfredi (1998). SVO ergativity and abstract ergativity. Recherches linguistiques de Vincennes 27: 71-94.

Delfitto, Denis (2002). Genericity in Language. Issues of Syntax, Logical Form and Interpretation. Alessandria: Edizioni dell'Orso.

Delfitto, Denis (2003). Facts in syntax and semantics. Unpublished manuscript, Università di Verona.

Delfitto, Denis \& Jan Schroten (1991). Bare plurals and the number affix in DP. Probus 3: $155-185$.

De Swart, Henriëtte \& Donka Farkas (2003). The Semantics of Incorporation: from Argument Structure to Discourse Transparency. (Stanford Monographs in Linguistics) Stanford: CSLI Publications.

Diesing, Molly (1992). Indefinites. (Linguistic Inquiry Monograph, 20) Cambridge: MIT Press.

Dobrovie-Sorin, Carmen (1994). The Syntax of Romanian: Comparative Studies in Romance. (Studies in Generative Grammar, 40) Berlin/New York: Mouton de Gruyter.

Dobrovie-Sorin, Carmen \& Brenda Laca (1996). Generic bare NPs. Unpublished manuscript, Université de Paris 7/Université de Strasbourg.

Ebert, Karen (1970). Referenz, Sprechsituation und die bestimmten Artikel in einem Nordfriesischen Dialekt. Unpublished Ph.D. dissertation, Universität Kiel.

Emonds, Joseph (1978). The verbal complex V'-V in French. Linguistic Inquiry 9: 151-175.

Fassi Fehri, Abdelkader (2003). Nominal classes and parameters across interfaces and levels, with particular reference to Arabic. To appear in Linguistic Variation Yearbook.

Fava, Elisabetta (ed.) (2001). Teorie del significato e della conoscenza del significato. Milano: Unicopli.

Gerstner, Claudia \& Manfred Krifka (1987). An outline of genericity. SNS-Bericht 87-23, Universität Tübingen.

Giorgi, Alessandra \& Giuseppe Longobardi (1991). The Syntax of Noun Phrases. (Cambridge Studies in Linguistics, 57) Cambridge: Cambridge University Press.

Heim, Irene (1982). The semantics of definite and indefinite noun phrases. Ph.D. dissertation, University of Massachusetts at Amherst; now New York: Garland (1988).

Heycock, Caroline \& Roberto Zamparelli (2003). Coordinated bare definites. Linguistic Inquiry 34: $443-470$.

Holmberg, Anders \& Görel Sandström (1996). Scandinavian possessive constructions from a Northern Swedish viewpoint. In Microparametric Syntax and Dialect Variation. (Current Issues in Linguistic Theory, 139) James R. Black \& Virginia Motapanyane (eds.), 95-120. Amsterdam/Philadelphia: Benjamins.

Huang, C.T. James (1982). Logical relations in Chinese and the theory of grammar. Unpublished Ph.D. dissertation, MIT.

Kamp, Hans (1981). A theory of truth and semantic representation. In Formal Methods in the Study of Natural Language, Jeroen Groenendijk, Theo Janssen \& Martin Stokhof (eds.), 277-322. Amsterdam: Mathematical Center.

Kaplan, David (1978). Dthat. In Pragmatics. (Syntax and Semantics, 9), Peter Cole (ed.), 221253. New York: Academic Press.

Kayne, Richard (1994). The Antisymmetry of Syntax. (Linguistic Inquiry Monograph, 25) Cambridge: MIT Press.

Kayne, Richard (2003). Some notes on comparative syntax, with special reference to English and French. Unpublished manuscript, New York University. 
Kripke, Saul (1980). Naming and Necessity. Oxford/Cambridge: Blackwell.

Lazzeroni, Romano (1995). La baritonesi come segno dell'individuazione: il caso del vocativo indoeuropeo. Studi e Saggi Linguistici 35: 33-44.

Longobardi, Giuseppe (1987). Sulle piccole isole. Italia Dialettale 50: 215-219.

Longobardi, Giuseppe (1991). Proper names and the theory of N-movement in syntax and logical form. University of Venice Working Papers in Linguistics 9.

Longobardi, Giuseppe (1994). Reference and proper names. Linguistic Inquiry 25: 609-665.

Longobardi, Giuseppe (1996). The syntax of N-raising: a minimalist theory. OTS Working Papers $96-005$ : 1-55.

Longobardi, Giuseppe (1997). N-raising and place names. In Scribthair a ainm n-ogaim. Scritti in memoria di Enrico Campanile, Riccardo Ambrosini et al. (eds.), 521-533. Pisa: Pacini.

Longobardi, Giuseppe (2000a). The structure of DPs: some principles, parameters and problems. In Handbook of Syntactic Theory. (Blackwell Handbooks in Linguistics), Mark Baltin \& Chris Collins (eds.), 562-603. Cambridge/Oxford: Blackwell.

Longobardi, Giuseppe (2000b). Postverbal subjects and the mapping hypothesis. Linguistic Inquiry 31: 691-702.

Longobardi, Giuseppe (2001). How comparative is semantics? A unified parametric theory of bare nouns and proper names. Natural Language Semantics 9: 335-369.

May, Robert (1977). The grammar of quantification. Unpublished Ph.D. dissertation, MIT.

May, Robert (1985). Logical Form. Its Structure and Derivation. (Linguistic Inquiry Monograph, 12) Cambridge: MIT Press.

Moro, Andrea (1997). The Raising of Predicates: Predicative Noun Phrases and the Theory of Clause Structure. (Cambridge Studies in Linguistics, 80) Cambridge: Cambridge University Press.

Müller, Ana \& Fátima Oliveira (2004). Bare nominals and number in Brazilian and European Portuguese. To appear in Journal of Portuguese Linguistics.

Munn, Alan \& Cristina Schmitt (1999a). Against the nominal mapping parameter: bare nouns in Brazilian Portuguese. Unpublished manuscript, ZAS Berlin/Michigan State University.

Munn, Alan \& Cristina Schmitt (1999b). Bare nouns and the morphosyntax of number. Unpublished manuscript, Michigan State University.

Napoli, Ernesto (undated). Reference. Unpublished manuscript, Università di Padova.

Neale, Stephen (1990). Descriptions. (A Bradford Book) Cambridge: MIT Press.

Pollock, Jean-Yves (1989). Verb movement, universal grammar, and the structure of IP. Linguistic Inquiry 20: 365-424.

Roodenburg, Jasper (2003). French bare nouns are not extinct. Unpublished manuscript, Universiteit van Amsterdam/Université de Paris 8. To appear in Linguistic Inquiry.

Smith, Carlota (1964). Determiners and relative clauses in a generative grammar of English. Language 40: $37-52$.

Stowell, Timothy (1981). Origins of phrase structure. Unpublished Ph.D. dissertation, MIT.

Stowell, Timothy (1989). Subjects, specifiers, and X-bar theory. In Alternative Conceptions of Phrase Structure, Mark Baltin \& Anthony Kroch (eds.), 232-262. Chicago IL: University of Chicago Press.

Stowell, Timothy (1991). Determiners in NP and DP. In Views on Phrase Structure: Papers Presented at a Conference Held at the University of Florida, Gainesville, in March 1989. (Studies in Natural Language and Linguistic Theory, 25), Katherine Leffel \& Denis Bouchard (eds.), 37-56. Dordrecht: Kluwer.

Szabolcsi, Anna (1987). Functional categories in the noun phrase. In Approaches to Hungarian, Vol. 2, István Kenesei (ed.), 167-189. Szeged: Jate.

Szabolcsi, Anna (1994). The noun phrase. In The Syntactic Structure of Hungarian. (Syntax and Semantics, 27), Ferenc Kiefer \& Katalin É. Kiss (eds.), 179-274. San Diego: Academic Press.

Timberlake, Alan (1977). Reanalysis and actualization in syntactic change. In Mechanisms of Syntactic Change, Charles Li (ed.), 141-180. Austin/London: University of Texas Press. 
Torrego, Esther (1988). Evidence for determiner phrases. Unpublished manuscript, University of Massachusetts at Boston.

Valois, Daniel (1991). The internal syntax of DP. Unpublished Ph.D. dissertation, UCLA.

Vangsnes, Øystein A. (2000). The identification of functional architecture. Unpublished Ph.D. dissertation, Universitetet Bergen.

Vergnaud, Jean-Roger (1974). French relative clauses. Unpublished Ph.D. dissertation, MIT.

Vergnaud, Jean-Roger \& Maria Luisa Zubizarreta (1992). The definite determiner and the inalienable constructions in French and English. Linguistic Inquiry 23: 595-652.

Zamparelli, Roberto (1995). Layers in the determiner phrase. Unpublished Ph.D. dissertation, University of Rochester. 